\title{
The PPARY agonist pioglitazone prevents TGF- $\beta$ induced renal fibrosis by repressing EGR-1 and STAT3
}

\author{
Ágnes Németh, Miklós M. Mózes ${ }^{1}$, Laurent Calvier², Georg Hansmann² and Gábor Kökény ${ }^{1 *}$ (D)
}

\begin{abstract}
Background: It has been proposed that peroxisome proliferator-activated receptor- $\gamma$ (PPARY) agonists might reduce renal fibrosis, however, several studies had contradictory results. Moreover, the possible interaction of TGF- $\beta_{1}$, PPARY, and transcription factors in renal fibrosis have not been investigated. We hypothesized that oral pioglitazone treatment would inhibit TGF- $\beta$-driven renal fibrosis and its progression, by modulating profibrotic transcription factors in TGF- $\beta_{1}$ transgenic mice.

Methods: Male C57BI/6 J mice (control, CTL, $n=14$ ) and TGF- $\beta$ overexpressing transgenic mice (TGF $\beta, n=14$, having elevated plasma TGF- $\beta_{1}$ level) were divided in two sets at 10 weeks of age. Mice in the first set were fed with regular rodent chow (CTL and TGF $\beta, n=7 /$ group). Mice in the second set were fed with chow containing pioglitazone (at a dose of $20 \mathrm{mg} / \mathrm{kg} /$ day, CTL + Pio and TGF $\beta+$ Pio, $n=7 / \mathrm{group})$. After 5 weeks of treatment, blood pressure was assessed and urine samples were collected, and the kidneys were analyzed for histology, mRNA and protein expression.

Results: TGF- $\beta_{1}$ induced glomerulosclerosis and tubulointerstitial damage were significantly reduced by pioglitazone. Pioglitazone inhibited renal mRNA expression of all the profibrotic effectors: type-lll collagen, TGF- $\beta_{1}$, CTGF and TIMP-1, and alike transcription factors CFos/cJun and protein expression of EGR-1, and STAT3 protein phosphorylation.

Conclusions: Oral administration of PPARY agonist pioglitazone significantly reduces TGF- $\beta_{1}$-driven renal fibrosis, via the attenuation of EGR-1, STAT3 and AP-1. This implies that PPARY agonists might be effective in the treatment of chronic kidney disease patients.
\end{abstract}

Keywords: Kidney, Renal fibrosis, PPARY, TGF- $\beta$, Transcription factors

\section{Background}

Renal fibrosis is the hallmark of several chronic kidney diseases (diabetes mellitus, arterial hypertension) that progress to end-stage renal disease (ESRD), and thus produce a serious health burden worldwide [1]. The dynamic balance of extracellular matrix protein (ECM) synthesis and degradation is mainly regulated by matrix metalloproteinases (MMPs) and their inhibitors, the tissue inhibitors of metalloproteinases (TIMPs). In fibrosis that occurs in multiple organs, this MMP/TIMP balance is disrupted. Transforming growth factor- $\beta_{1}\left(\right.$ TGF- $\left.\beta_{1}\right)$ is a multifunctional cytokine involved in various pathologic

\footnotetext{
* Correspondence: kokeny.gabor@med.semmelweis-univ.hu 1 Department of Pathophysiology, Semmelweis University, Nagyvárad tér 4, Budapest $\mathrm{H}-1089$, Hungary

Full list of author information is available at the end of the article
}

conditions, including carcinogenesis, and tissue fibrosis $[2,3]$. TGF- $\beta_{1}$ signaling can induce TIMP-1 transcription at promoter level via activator protein-1 complex (AP-1) [4]. TGF- $\beta_{1}$ transgenic mice with elevated plasma levels of TGF- $\beta_{1}$ develop severe renal fibrosis, underscoring the central role of TGF- $\beta_{1}$ in the pathogenesis of fibrotic kidney diseases [5].

Among the several profibrotic transcription factors, early growth response factor-1 (EGR-1) contributes to fibrosis by directly stimulating collagen synthesis [6] and myofibroblast differentiation [7]. The Janus kinase family (JAK) and the signal transducers and activators of transcription (STATs) signaling pathways also play important role in several models of renal diseases [8-10]. STAT3 influences cell proliferation [11-13] and fibrosis [14] by inducing the expression of multiple genes, including 
TGF- $\beta_{1}$ [15]. Conversely, we identified a novel noncanonical, proliferative TGF- $\beta_{1}$-pSTAT3-pFoxO1 signaling axis in vascular smooth muscle cells [16].

Peroxisome proliferator-activated receptor- $\gamma$ (PPAR $\gamma$ ) is an ubiquitary, anti-fibrotic and vasoprotective nuclear hormone receptor and transcription factor. PPAR $\gamma$ agonists (e.g. pioglitazone) have been widely used in the treatment of diabetes mellitus [17] and the prevention of macrovascular events and the development of diabetes in patients with insulin resistance [18].

Moreover, PPAR $\gamma$ agonists have been also shown to reduce renal damage in animal models of ischemia reperfusion injury, autosomal dominant polycystic kidney disease (ADPKD) or nondiabetic chronic kidney diseases [19]. Interestingly, despite a beneficial effect of the (otherwise liver-toxic) PPAR $\gamma$ agonist troglitazone was reported in the unilateral ureter obstruction (UUO) model of renal fibrosis [20], others could not confirm these results using pioglitazone [21]. In addition to these conflicting results, the possible interaction of PPAR $\gamma$, TGF- $\beta_{1}$ and EGR-1 in renal fibrosis has not been investigated.

Here, we aimed to study whether the chronic administration of PPAR $\gamma$ agonist pioglitazone could influence renal EGR-1, STAT3 and AP-1 expression, and ameliorate renal fibrosis in TGF- $\beta_{1}$ overexpressing mice. We report that oral administration of pioglitazone effectively reduced glomerulosclerosis, tubular injury and interstitial fibrosis by inhibiting EGR-1 and TIMP-1 expression. Our results might help to clarify the beneficial role of PPAR $\gamma$ in preventing or reversing TGF $\beta_{1}$-driven renal fibrosis.

\section{Methods}

Animals and experimental design

Male C57Bl6/J (B6) and B6-Alb/TGF- $\beta_{1}\left(\mathrm{cys}^{223,225}\right.$ ser) [5] (TGF- $\beta 1$ transgenic mice with elevated circulating TGF$\beta_{1}$ level) were housed at the Semmelweis University NET GMO facility under standard specific pathogen free (SPF) conditions, with a $12 / 12 \mathrm{~h}$ light/dark cycle. In TGF- $\beta 1$ transgenic mice, the transgene construct consists of the full-length porcine TGF- $\beta 1 \mathrm{cDNA}$ (with mutated cysteine 223 and 225 to serine which leads to production of active TGF- $\beta 1$ ) driven by the albumin promoter and enhancer, and the transgene was incorporated into the $\mathrm{Y}$ chromosome therefore only male mice are transgenic. The expression of the transgene starts after birth in the hepatocytes, and leads to constitutive secretion of active TGF- $\beta 1$ into the bloodstream. The mouse strains were bred and maintained at the NET GMO SPF facility. The animals had free access to standard rodent chow (Altromin 1314 TPF) and filtered drinking water. 10 week old male C57Bl/6 J control (CTL) and TGF- $\beta_{1}$ transgenic mice (TGF $\beta$ ) were randomly divided in two sets. The number of animals was calculated by the
Ethical Committee to provide the minimum sample size needed for relevant results. The first set of mice received regular chow. The second set of mice were treated orally with pioglitazone $(20 \mathrm{mg} / \mathrm{kg} /$ day) for 5 weeks $(\mathrm{CTL}+$ Pio and TGF $\beta+$ Pio). Pioglitazone was incorporated in the chow, and average food consumption was assessed at the beginning of the study. Sample size was $n=7 /$ group. At 15 weeks of age, urine spot samples were obtained by sterile punction of the bladder under isoflurane $(2 \%)$ anesthesia, blood pressure was measured and mice were perfused by intracardiac cannula under narcosis for 20 min with $4{ }^{\circ} \mathrm{C}$ physiological saline. Then, mice were euthanized with $5 \%$ isoflurane and kidneys were harvested for histology and mRNA expression analyses. All assays were performed in duplicates for each sample to ensure reliability of single values.

\section{Animal genotyping}

The presence of TGF- $\beta_{1}$ transgene was verified from genomic DNA (1-2 mm tail samples) by polymerase chain reaction (PCR). DNA was extracted by Tris- $\mathrm{NaOH}$ method. Briefly, samples were incubated in $200 \mu \mathrm{l}$ of 0.1 $\mathrm{N} \mathrm{NaOH}$ in a microcentrifuge tube at $96^{\circ} \mathrm{C}$ for $10 \mathrm{~min}$, mixed and cooled on ice. After briefly spun, $50 \mu \mathrm{l}$ Tris $(\mathrm{pH} 8)$ was added to the lysates, mixed and centrifuged at $20000 \mathrm{~g}$ for $6 \mathrm{~min}$ at $4{ }^{\circ} \mathrm{C}$. Supernatants were pipetted into a new tube, and $2.5 \mu \mathrm{l}$ of each supernatant was used for the PCR.

The following Alb/TGFb primer sequences were used: sense: 5'-GGCAAACATACGCAAGGGA-3'; antisense: 5'-AGAATCTGGCCGCGAATGG-3'. The PCR reactions were the following: initial denaturation at $95^{\circ} \mathrm{C}$ for $2 \mathrm{~min}$, then 35 cycles of $95^{\circ} \mathrm{C}$ for $50 \mathrm{~s}, 65^{\circ} \mathrm{C}$ for $50 \mathrm{~s}$ and $72{ }^{\circ} \mathrm{C}$ for $75 \mathrm{~s}$. The PCR products were separated on $1.5 \%$ agarose gels to detect the 370 base pair product of the transgene [22].

\section{Measurement of blood pressure}

Systemic blood pressure was measured invasively under isoflurane analgesia, followed by organ harvest. A $1.4 \mathrm{~F}$ microtip catheter (Millar Instruments, USA) inserted into the right carotid artery/ aortic arch where the systemic blood pressure was measured. Blood pressure curves were recorded and analyzed using a PowerLab recording unit and LabChart software (AD Instruments, Colorado Springs, USA).

\section{Determination of plasma TGF- $\beta_{1}$ levels}

During harvest, blood samples from the aorta were harvested in siliconized microcentrifuge tubes containing EDTA as anticoagulant (100 $\mu \mathrm{l} /$ mouse). Blood samples were centrifuged at $1000 \mathrm{~g}$ for $20 \mathrm{~min}$ and the isolated plasma was centrifuged again in new siliconized tubes at $10000 \mathrm{~g}$ for $10 \mathrm{~min}$. Supernatants $(10 \mathrm{ul})$ were used to 
determine plasma TGF- $\beta_{1}$ level using a commercial ELISA kit (R\&D Quantikine TGF- $\beta_{1}$ ELISA, Minneapolis, USA).

\section{Determination of proteinuria}

The amount of excreted protein (BCA assay, Thermo Fisher, Waltham, MA, USA) and creatinine (Creatinine Kit, Diagnosticum ZRt, Budapest, Hungary) were measured from spot urine samples according to the manufacturer's protocols. Proteinuria was expressed as urinary protein to creatinine ratio (UPCR), in order to normalize for GFR.

\section{Histology and immunohistochemistry}

Formaline fixed paraffin embedded kidney sections were evaluated after Masson's trichrome staining. The degree of glomerulosclerosis and tubulointerstitial damage was determined blinded on a semiquantitative scale as previously described [23].

Briefly, glomerulosclerosis index (GSI) of each animal was determined with a light microscope at 400x magnification from the arithmetic mean of 100 evaluated glomeruli. The tubulointerstitial damage index (TDI) scores were evaluated at 100x magnification as follows: score 0: no change; score 1-5 depending on the criteria have been met in the given field of view: tubular dilatation, tubular atrophy, hyalin in tubular lumen, interstitial infiltration of mononuclear cells, interstitial fibrosis.

Immunohistochemical staining of paraffin embedded sections was performed using avidin-biotin method as previously described [23] using citrate buffer $\mathrm{pH} 6.0$ for heat induced antigen retrieval. The primary antibodies were rabbit polyclonal anti-fibronectin at 1:1000 (SigmaAldrich, Budapest), and rabbit polyclonal anti-EGR-1 at 1:500 (Cell Signaling, USA).

Immunostaining reactivitiy scores were evaluated in a blinded manner at 400x magnification using a semiquantitative scoring method: score 0: no staining; score 1: light staining; score 2: moderate staining; score 3: strong staining; score 4: very strong staining. Renal EGR-1 expression was assessed by counting the amount of EGR-1 positive nuclei at 400x magnification (high power field, HPF) and expressed as positive cells / HPF.

\section{Gene expression analysis}

RNA was isolated from total kidney homogenates $(20-30 \mathrm{mg})$ by classical phenol-chloroform extraction (Trizol, Thermo Fisher) according to the manufacturer's protocol. The RNA concentration was measured photometrically with NanoDrop (Thermo Fisher). Reverse transcription of $1 \mu \mathrm{g}$ RNA was performed using High Capacity cDNA Reverse Transcription kit (Applied Biosystems, Forster City, CA, USA). Each PCR reaction was measured by BioRad CFX96 device (BioRad, USA), using Bioline SensiFast SYBR Green
PCR Master Mix (Bioline, Germany) The specificity and effectivity of PCR reactions were verified by melting curve analysis. Each sample was measured in duplicate and normalized for ribosomal 18S RNA expression using the $2^{-\Delta C t}$ formula. Primer sequences were as follows: $m A$ Acta 2 forward: ATAACCCTTCAGCGTTCAGC; mActa2 reverse: ACATAGCTGGAGCAGCGTC; $m$ Colla1 forward: CATA AAGGGTCATCGTGGCT; mColla1 reverse: TTGA GTCCGTCTTTGCCAG; $m$ Col3a1 forward: TGGAAAAG ATGGAACAAGTGG; $m$ Col3a1 reverse: CCAGACTT TTCACCTCCAAC; $m$ Ctgf forward: CCCGAGTTACCAATGACAATAC; $m$ Ctgf reverse: CTTAGCCCTGT ATGTCTTCAC; $m$ Fos forward: TTTCAACGCCGACTACGAGG; $m$ Fos reverse: GCGCAAAAGTCCTGTGTGTT; mJun forward: GCACATCACCACTACACCGA; mJun reverse: GGGAAGCGTGTTCTGGCTAT; $m L c n 2$ forward: ACGTCACTTCCATCCTCGTC; $m L c n 2$ reverse: CCTG GAGCTTGGAACGAATG; $m M m p 9$ forward: TGGA TAAGGAGTTCTCTGGTG; $m M m p 9$ reverse: CCAC CTTGTTCACCTCATTTT; $m$ Tgfb1 forward: CACCATCCATGACATGAACC; $m$ Tgfbl reverse: TCATGTTGGACAACTGCTCC; mTimp1 forward: CACCAGAGCAGA TACCATG; mTimp1 reverse: GTGGTCTCGTTGATT TCTGG. The individual gene expression levels in each experimental group were normalized to a calibrator (control sample) in order to exclude unwanted sources of variation, and each gene expression values are expressed as fold expression relative to this control sample.

\section{Statistics}

Experimental data are presented as mean \pm SD and statistical analysis was performed using SPSS 10 for Windows (SPSS Inc). The data were analyzed using Kruskal-Wallis test followed by Dunn's multiple comparison test. The level of significance was set to $p<0.05$. The data and statistical analysis comply with the recommendations on experimental design and analysis in pharmacology [24].

\section{Results \\ Murine plasma TGF- $\beta_{1}$ levels, body weight and blood pressure}

Both wild type control mice and TGF- $\beta_{1}$ transgenic animals were evaluated for the absence or presence of the transgene. Control mice did not show the amplification of transgene, while transgenic mice showed the porcine TGF- $\beta_{1}$ PCR product (Additional file 1: Figure S1). Accordingly, the plasma TGF- $\beta_{1}$ levels of transgenic mice was significantly elevated as compared to control mice (Additional file 1: Figure S1).

Both control and TGF- $\beta_{1}$ transgenic mice had similar body weight regardless of the treatment (Fig. 1b), and the mean arterial blood pressure was also similar in all groups (Fig. 1a). 
a

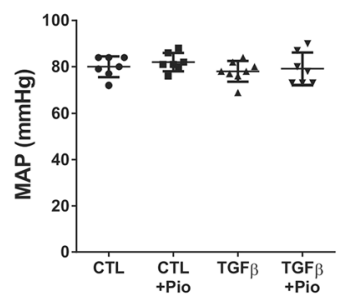

d
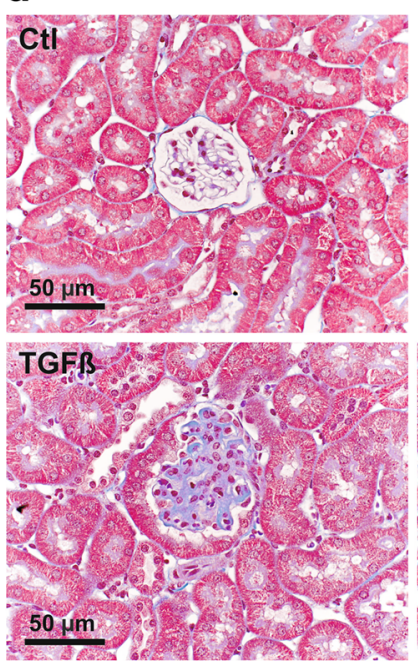

f

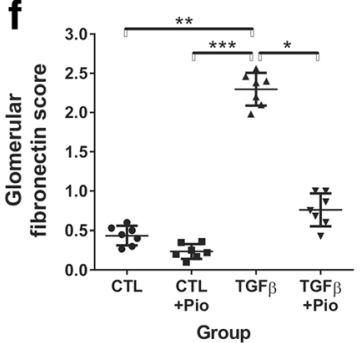

b
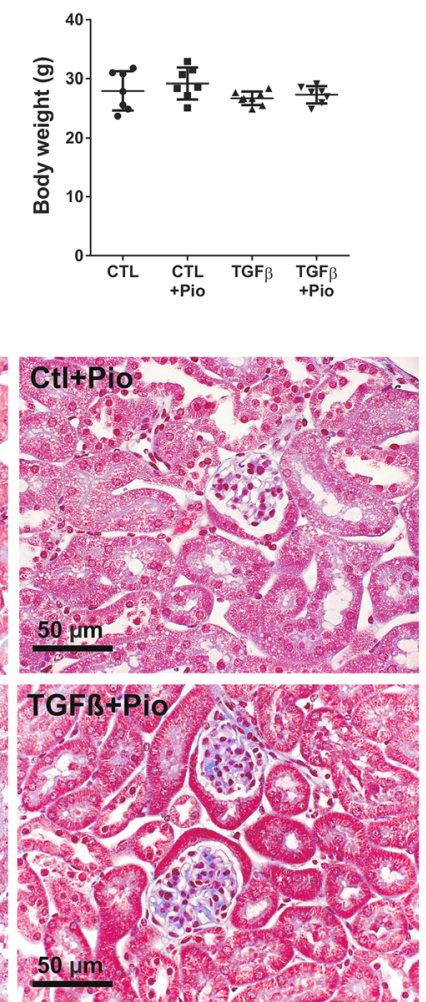

C

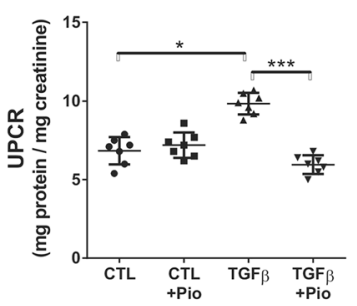

e
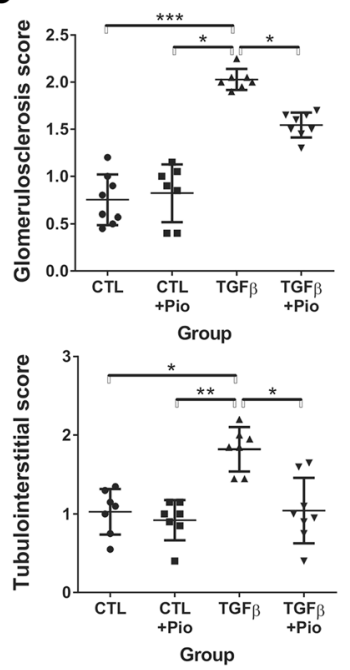

Fig. 1 The values of mean arterial pressure, body weights, urinary protein/creatinine ratio and renal histology. Both mean arterial blood pressure (MAP, a) and body weight of control and transgenic mice (b) was similar in all groups regardless of treatment. Urinary protein/creatinine ratio (UPCR) was elevated in untreated TGF- $\beta_{1}$ transgenic mice (c), but was significantly ameliorated by pioglitazone treatment. Renal histology depicted significant glomerulosclerosis and tubulointerstitial damage in untreated TGF- $\beta_{1}$ mice (d and e) that were reduced by pioglitazone (Masson's trichrome staining, 400X magnification, bar represents $50 \mu \mathrm{m}$ ). Fibronectin immunostaining was markedly stronger in both glomeruli and tubulointerstitium of untreated TGF- $\beta_{1}$ mice (f), but reduced to control levels in pioglitazone treated mice $\left(n=7 /\right.$ group, ${ }^{*}: p<0.05,{ }^{* *}: p<0.01,{ }^{* * *}: p<0.001$, Kruskal-Wallis test)

\section{Pioglitazone ameliorates TGF- $\beta_{1}$ induced proteinuria, glomerular and tubular injury}

Urinary protein/creatinine ratio (UPCR) was similar in both the pioglitazone treated and non-treated controls. In contrast, UPCR was elevated by $40 \%$ in untreated TGF- $\beta_{1}$ transgenic mice, as compared to controls, but was significantly reduced to near normal levels in pioglitazone treated transgenic mice (Fig. 1c.).

Kidneys of control animals depicted normal histology without signs of glomerular or tubular damage, independent of the therapy (Fig. 1d and e). In contrast, and consistent with the UPCR results, untreated TGF- $\beta_{1}$ transgenic kidneys depicted extensive glomerulosclerosis and significant tubulointerstitial damage, accompanied by marked renal fibronectin immunoreactivity (Fig. 1f). Pioglitazone treatment reduced the TGF- $\beta_{1}$ induced glomerulosclerosis and tubulointerstitial damage by $30 \%$ and by $50 \%$, respectively (Fig. 1d and e), and normalized fibronectin expression (Fig. 1f).

In line with our histological findings, mRNA expression levels of Lipocalin-2 (Lcn2, a sensitive biomarker of tubular damage [25]) were similar in the pioglitazone treated and non-treated controls. In contrast, Lcn2 expression was significantly elevated in untreated TGF- $\beta_{1}$ 


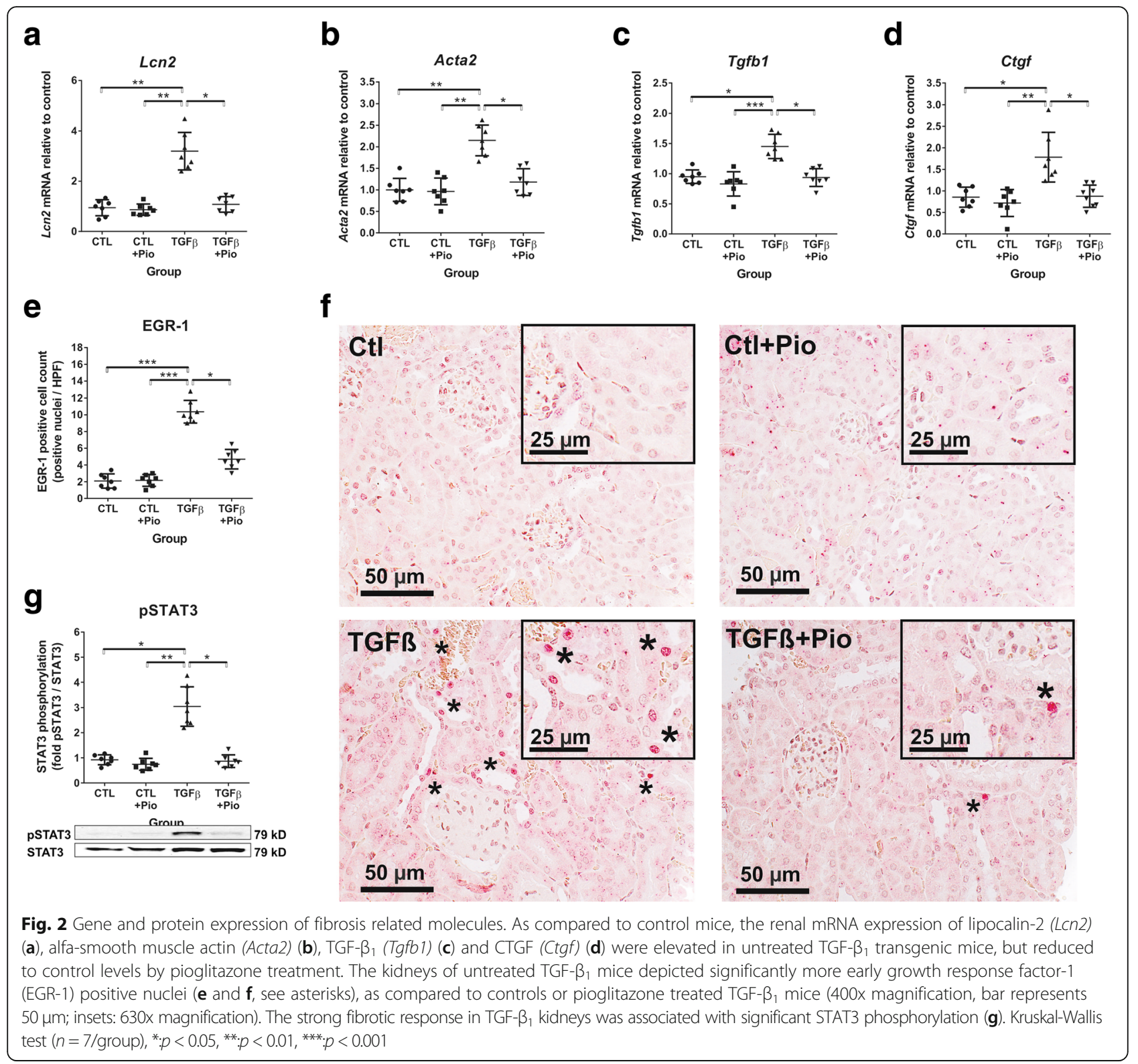

transgenic mice but reduced to near normal levels in pioglitazone treated transgenic mice (Fig. 2a).

\section{Pioglitazone improves TGF- $\beta_{1}$ induced renal fibrosis and transcription factor expression}

During renal fibrosis, myofibroblasts express $\alpha$-smooth muscle actin (Acta2), and TGF- $\beta_{1}$ transgenic kidneys overexpressed Acta2 by 2 -fold as compared to controls. Pioglitazone treatment was able to reduce Acta2 expression to near control levels (Fig. 2b).

Among the profibrotic growth factors, renal expression of both TGF- $\beta_{1}$ (Tgfb1) and CTGF (Ctgf) mRNA were significantly reduced by pioglitazone treatment (Fig. 2c and d). Similarly, we found strong EGR-1 immunoreactivity in TGF- $\beta_{1}$ transgenic kidneys that was attenuated by pioglitazone treatment (Fig. 2e and f).

We observed marked STAT3 phosphorylation in the kidneys of untreated TGF- $\beta_{1}$ transgenic mice, as compared to control groups, that was normalized by pioglitazone administration (Fig. 2g).

In accordance with the pro-fibrotic effect of circulating TGF- $\beta_{1}$ in transgenic mice, the renal expression of type I (Col1a1) and type III collagens (Col3a1) were 3-fold higher as compared to controls, but significantly attenuated by pioglitazone treatment (Fig. $3 \mathrm{a}$ and b). The increased production of extracellular matrix components was accompanied by a 10 -fold overexpression of TIMP1 mRNA (Timp1) in untreated transgenic mice, accompanied by strikingly reduced renal MMP-9/TIMP-1 
a

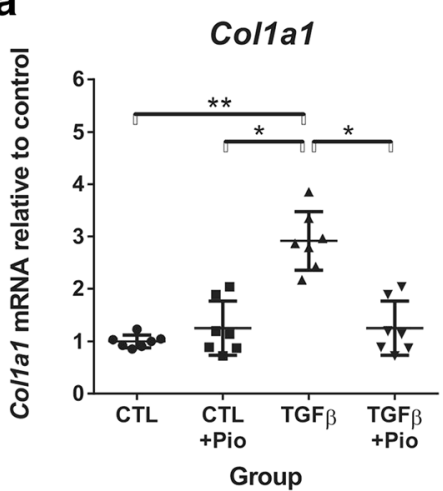

c

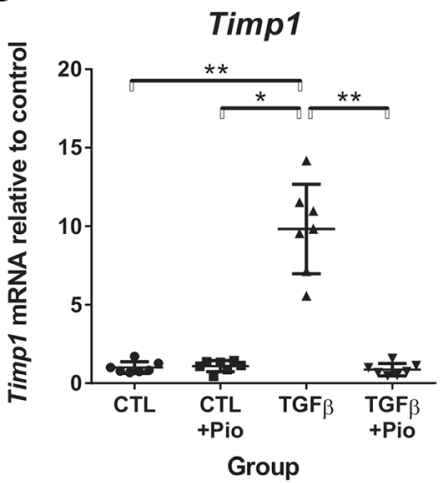

e

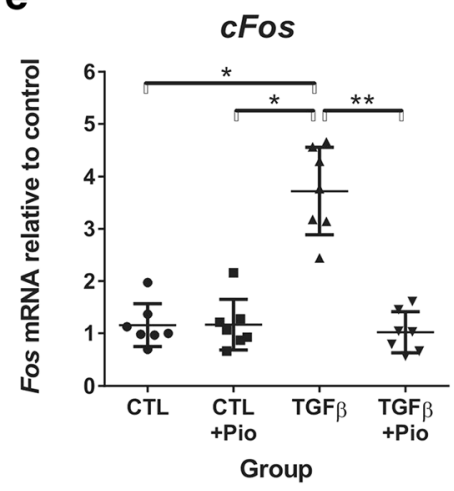

b

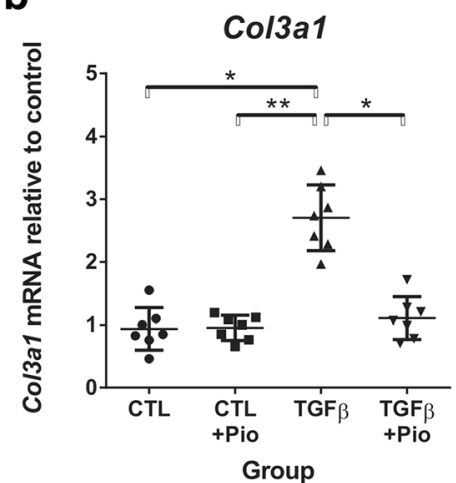

d

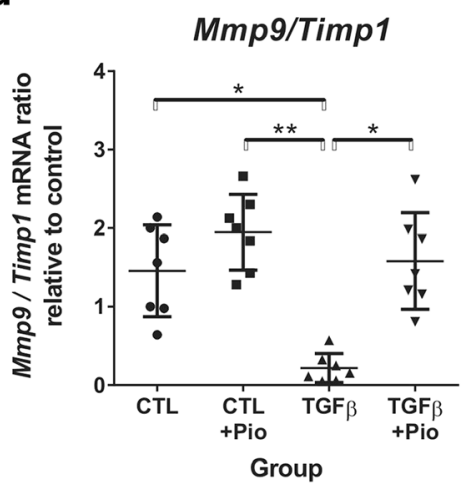

f

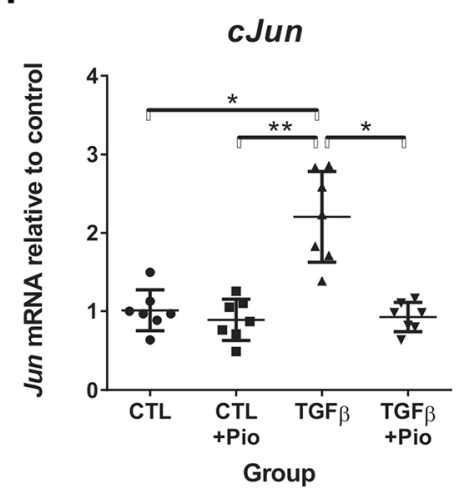

Fig. 3 Gene expression of extracellular matrix components and activator-protein 1 components. The mRNA expression of type I (Colla1) and type III (Co/3a1) collagens were significantly elevated in TGF- $\beta_{1}$ kidneys (a, b), accompanied by marked TIMP-1 mRNA (Timp1) overexpression (c) with reduced MMP-9/TIMP-1 ratio (d) which were attenuated by pioglitazone. Kidneys of untreated TGF- $\beta_{1}$ mice also had elevated cFos and clun expression, normalized by pioglitazone treatment (e, $\mathbf{f}$. Kruskal-Wallis test $(n=7 /$ group), $*: p<0.05, * *: p<0.01$

ratio, as compared to controls (Fig. 2c and d). Pioglitazone dampened Timp1 overexpression in transgenic mice and normalized the MMP-9/TIMP-1 ratio without any effect on the control groups (Fig. $2 \mathrm{c}$ and d).

The observed Timp1 overexpression in TGF- $\beta_{1}$ transgenic kidneys was accompanied by 4 -fold and 2 -fold increase in mRNA expression of the AP-1 components cFos and cJun, respectively (Fig. 2e and f), all of which were completely blocked (to control levels) by oral pioglitazone treatment (Fig. 2e and f).

\section{Discussion}

In the present study, we examined the effect of PPAR $\gamma$ activation on the transcriptional regulation of renal fibrosis in TGF- $\beta_{1}$ transgenic mice. To the best of our knowledge, this is the first report demonstrating that the PPARY agonist pioglitazone reduced kidney fibrosis in association with dampened renal EGR-1 and TIMP-1 expression.

PPARY agonists (e.g. pioglitazone) have been widely used in the treatment of pre-diabetes and diabetes 
mellitus $[18,26]$. However, its effects on renal fibrosis in animal models of renal ischemia reperfusion injury, autosomal dominant polycystic kidney disease (ADPKD) or nondiabetic chronic kidney diseases have been ambigous [19,21], and yet, the possible role of transcription factors have not been elucidated.

In our study, neither the several fold increased plasma TGF- $\beta_{1}$ concentration, nor pioglitazone treatment had any influence on the mean arterial blood pressure of mice. This is in contrast to some reports on PPAR $\gamma$ agonists having antihypertensive effects, caused by increased endothelial NO levels and inhibition of ANG II [27]. However, several other studies did not find changes in systemic blood pressure with PPAR $\gamma$ agonist treatment (rosiglitazone) in wild type mice on regular and high fat diet [28]. Our study does support the beneficial effect of PPAR $\gamma$ agonists on reducing proteinuria, as previously shown in hypertensive and diabetes animal models [20], as well as T2DM patients [27]. Accordingly, pioglitazone significantly ameliorated both glomerular and tubulointerstitial fibrotic changes in the TGF- $\beta_{1}$ transgenic mice, associated with decreased expression of lipocalin-2, a sensitive biomarker of tubular damage [25]). Along with these findings, mRNA expression of fibronectin, type I and type III collagens, and TGF- $\beta_{1}$ were reduced, all known hallmarks of renal fibrosis [29-31]. Increased renal TGF- $\beta_{1}$ level promotes endothelial-mesenchymal transition (EMT) and progressive renal interstitial fibrosis [32]. CTGF, as one of the downstream TGF- $\beta_{1}$ mediators, participates in fibroblast proliferation and ECM production [19]. In our study, oral pioglitazone administration inhibited the TGF- $\beta_{1}$-driven CTGF mRNA expression. The anti-fibrotic and antiproliferative effect of pioglitazone in our studies is supported by animal models of $5 / 6$ nephrectomy [33], passive Heymann nephritis [34], acute mesangial proliferative glomerulonephritis, UUO [20] and ischemia reperfusion injury [35]. We have recently demonstrated that pioglitazone attenuates TGF- $\beta_{1}$ induced pulmonary arterial hypertension and remodeling in the TGF- $\beta_{1}$ overexpressing mouse, via decreasing TGF- $\beta_{1}$, CTGF and $\alpha$-smooth muscle actin (Acta2) expression in pulmonary arterial SMC [16]. Furthermore, PPAR $\gamma$ agonists might directly inhibit TGF- $\beta_{1}$ expression and reduce interstitial myofibroblast accumulation [20]. In our current study, the reduced $\alpha$-smooth muscle actin and renal TGF- $\beta_{1}$ expressions support the proposed inhibitory effect of PPAR $\gamma$ agonists on myofibroblast activation and ECM production in fibrotic kidneys [36].

TGF- $\beta_{1}$ not only induces the synthesis of ECM components but also reduces matrix degradation via tissue inhibitors of metalloproteinases (TIMPs) [37]. Untreated TGF- $\beta_{1}$ transgenic mice in our study had disrupted renal MMP/TIMP balance that, intriguingly, was normalized by pioglitazone treatment. The latter could be, on one hand, a direct consequence of the reduced renal TGF- $\beta_{1}$ expression. On the other hand, pioglitazone might have indirect effect on the MMP/TIMP balance via transcriptional modulation. As TIMP-1 transcription is partly regulated by the activator protein-1 (AP-1) complex, we investigated the expression of the AP-1 components cFos and cJun [4], that were significantly increased in untreated TGF- $\beta_{1}$ transgenic kidneys. Consistent with our proposal, both cFos and cJun expression was normalized by pioglitazone treatment. Our findings not only support the regulatory importance of AP-1 transcription complex, but also show that PPAR $y$ counteracts AP-1 activation.

Other transcription factors, such as the immediate early gene EGR-1, might be induced by a variety of fibrogenic stimuli, directly stimulating collagen production, matrix accumulation and myofibroblast differentiation [6, 7]. We found boosted EGR-1 expression in untreated TGF- $\beta_{1}$ transgenic kidneys that was attenuated by pioglitazone treatment. Although the relationship of EGR-1 and PPARY in the kidney has not been investigated yet, the PPAR $\gamma$ agonist rosiglitazone decreased skin fibrosis and EGR-1 levels in a mouse model of scleroderma [38]. This latter finding supports our results and implicates that EGR-1 is a potential anti-fibrotic target of activated PPAR $\gamma$.

In addition, activation of the JAK/STAT pathways may be responsible for the increased myofibroblast transdifferentiation in the injured kidney [39]. STAT3 can induce TGF- $\beta_{1}$ expression [15], and STAT3 inhibition was reported to suppress tubulointerstitial fibrosis in UUO model [40]. Furthermore, we have recently demonstrated in human pulmonary arterial smooth muscle cells that TGF- $\beta_{1}$ induces STAT3 phosphorylation, and this STAT3 activation is inhibited by pioglitazone [16]. Our present study shows an additional potential interplay of STAT3 and PPARY in renal fibrosis, as STAT3 was activated in kidneys of untreated TGF- $\beta_{1}$ transgenic mice, but STAT3 activation was absent in kidneys of TGF- $\beta_{1}$ transgenic mice chronically treated with pioglitazone.

Based on our study, we postulate that PPAR $\gamma$ agonist pioglitazone exerts its antifibrotic effect in the kidney by repressing STAT3 activation as well as decreasing the expression of EGR-1 and AP-1 components (cFos, cJun) (Fig. 4).

\section{Conclusions}

To the best of our knowledge, this is the first study to show that oral administration of PPAR $\gamma$ agonist pioglitazone in fibrosis prone TGF- $\beta_{1}$ transgenic mice antagonized the profibrotic effects of TGF- $\beta_{1}$ by repressing EGR-1, STAT3 and AP-1. In addition, pioglitazone normalized the MMP/TIMP imbalance in the kidneys 


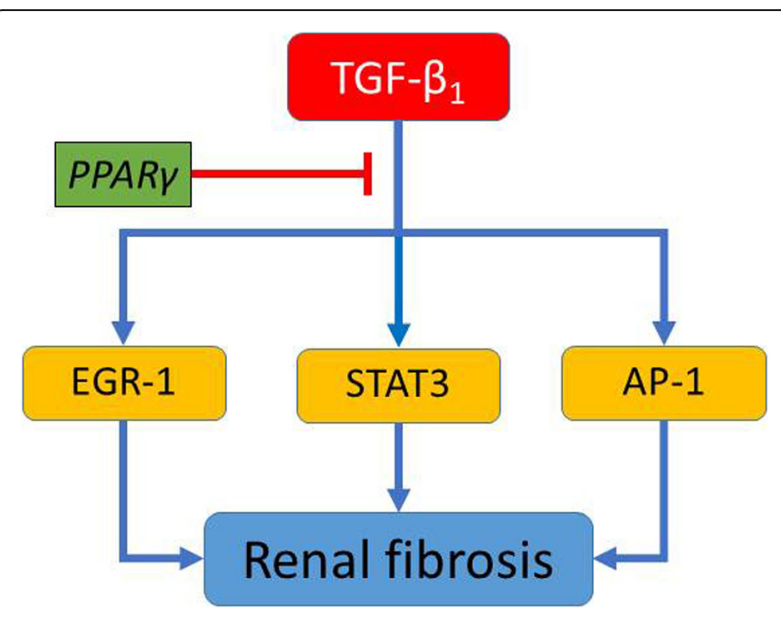

Fig. 4 Proposed novel mechanism how the PPARy agonist pioglitazone attenuates TGF- $\beta_{1}$ induced renal fibrosis. Our study shows that PPARY agonist pioglitazone repressed the transcription factors EGR-1, STAT3, and AP-1 (CFos, CJun), all of which are important signaling mediators in the pathomechanisms of TGF- $\beta_{1}$ driven renal fibrosis

without changing the systemic blood pressure. Our observations and previous reports suggest that PPAR $\gamma$ agonists might be effective in the future treatment of chronic kidney disease patients, especially in the context of heightened TGF- $\beta_{1}$ signaling.

As a limitation, we did not test the renal effect of direct STAT3 or EGR-1 inhibition in our model, eg. by using in vivo gene silencing approach. However, such expansion of our study would have increased the amount of animals needed, and would introduce a significant bias due to the intrarenal delivery problems of gene silencing oligonucleotides.

\section{Additional file}

Additional file 1: Figure S1. (a) Representative picture of genotyping the TGF- $\beta$ transgenic mice (samples 3,4 and 6 are transgenic, showing the $370 \mathrm{bp} \mathrm{PCR}$ product of the transgene; samples 1,2 and 5 are wild type controls). (b) Levels of circulating TGF- $\beta 1$ in wild type B6 control mice $(C T L)$ and transgenic mice (TGF $\beta$ ) at the beginning of the study clearly shows that transgenic mice had 3 -fold elevated plasma TGF- $\beta 1$ levels ( $n=14$ /group, $p<0.001$, Mann-Whitney test). (PDF $209 \mathrm{~kb}$ )

\footnotetext{
Abbreviations

Acta2: Gene of alfa-smooth muscle actin; AP-1: Activator protein-1; Col1a1: Gene of type I collagen alfa chain; Col3a1: Gene of type III collagen alfa chain; CTGF: Connective tissue growth factor; ECM: Extracellular matrix; EGR-1: Early growth response factor-1; ESRD: End-stage renal disease; Lcn2: Gene for lipocalin-2; MAP: Mean arterial blood pressure; MMP-9: Matrix metalloprotease-9; PPARY: Peroxisome proliferator-activated receptor- $\gamma$; PSTAT3: phosphorylated Signal transducers and activators of transcription-3; STAT3: Signal transducers and activators of transcription-3; Tgfb1: Gene of transforming growth factor- 1 1; TGF- 31 : Transforming growth factor- 31 ; TIMP1: Tissue inhibitor of matrix metalloprotease-1; UPCR: Urinary protein / creatinine ratio
}

\section{Acknowledgements}

The authors would like to thank the technical assistance of Krisztina Fazekas, Adrienn Orbán, Ildikó Virág (Semmelweis University, Inst. of Pathophysiology) and Magdolna Pekár (2nd Dept. of Pathology). Part of this work have been presented as a poster at the 54th ERA-EDTA congress (https://doi.org/10. 1093/ndt/gfx145.SP271).

\section{Author's contributions}

ÁN carried out the molecular studies and immunostainings, and helped to draft the manuscript. MMM supervised the molecular studies and edited the manuscript for important intellectual content. LC performed the invasive blood pressure measurements and the organ harvest. GH participated in study design, supervised the results, obtained funding, and edited the manuscript for important intellectual content. GK participated in the design of the study, supervised all molecular studies and immunostainings, obtained funding, drafted and edited the manuscript. All authors read and approved the final manuscript.

\section{Funding}

The project was funded by the grant of the Hungarian Scientific Research Fund (OTKA PD112960 to GK), and the German Research Foundation (DFG HA4348/2-2 and HA4348/6-1 to GH). None of the funding bodies had any role in the study design, data collection, analysis, interpretation or in writing the manuscript.

\section{Availability of data and materials}

The datasets used and/or analysed during the current study are available from the corresponding author on reasonable request.

\section{Ethics approval and consent to participate}

All procedures and handling of animals during the investigations were reviewed and approved by the local Ethical Committee for Animal Experimentation at Semmelweis University and the Directorate of Food Chain Safety and Animal Health of the Pest County Government Office (permission number PE/EA/948-4/ 2018) according to the EU Directive 2010/63/EU for animal experiments.

\section{Consent for publication}

Not applicable.

\section{Competing interests}

The authors declare no competing interests. The results presented in this paper have not been published previously in whole or part, except in abstract form.

\section{Author details}

'Department of Pathophysiology, Semmelweis University, Nagyvárad tér 4, Budapest H-1089, Hungary. ${ }^{2}$ Department of Pediatric Cardiology and Critical Care, Hannover Medical School, Hannover, Germany.

Received: 13 February 2019 Accepted: 23 June 2019

Published online: 05 July 2019

\section{References}

1. Kazancioglu R. Risk factors for chronic kidney disease: an update. Kidney Int Suppl (2011). 2013;3:368-71.

2. Massague J. TGF-beta signal transduction. Annu Rev Biochem. 1998;67:753-91.

3. Leask A, Abraham DJ. TGF-beta signaling and the fibrotic response. FASEB $J$. 2004;18:816-27.

4. Karin M, Liu Z, Zandi E. AP-1 function and regulation. Curr Opin Cell Biol. 1997;9:240-6.

5. Sanderson N, Factor V, Nagy P, Kopp J, Kondaiah P, Wakefield L, Roberts AB, Sporn MB, Thorgeirsson SS. Hepatic expression of mature transforming growth factor beta 1 in transgenic mice results in multiple tissue lesions. Proc Natl Acad Sci U S A. 1995;92:2572-6.

6. Mozes MM, Szoleczky P, Rosivall L, Kokeny G. Sustained hyperosmolarity increses TGF-ss1 and Egr-1 expression in the rat renal medulla. BMC Nephrol. 2017;18:209.

7. Bhattacharyya S, Fang F, Tourtellotte W, Varga J. Egr-1: new conductor for the tissue repair orchestra directs harmony (regeneration) or cacophony (fibrosis). J Pathol. 2013;229:286-97. 
8. Marrero MB, Banes-Berceli AK, Stern DM, Eaton DC. Role of the JAK/STAT signaling pathway in diabetic nephropathy. Am J Physiol Renal Physiol. 2006;290:F762-8

9. Martinez-Lostao L, Ordi-Ros J, Balada E, Segarra-Medrano A, Majo-Masferrer J, Labrador-Horrillo M, Vilardell-Tarres M. Activation of the signal transducer and activator of transcription-1 in diffuse proliferative lupus nephritis. Lupus. 2007; 16:483-8

10. Matsui F, Meldrum KK. The role of the Janus kinase family/signal transducer and activator of transcription signaling pathway in fibrotic renal disease. J Surg Res. 2012;178:339-45.

11. Kalechman Y, Gafter U, Weinstein T, Chagnac A, Freidkin I, Tobar A, Albeck M, Sredni B. Inhibition of interleukin-10 by the immunomodulator AS101 reduces mesangial cell proliferation in experimental mesangioproliferative glomerulonephritis: association with dephosphorylation of STAT3. J Biol Chem. 2004;279:24724-32.

12. Huang JS, Guh JY, Hung WC, Yang ML, Lai YH, Chen HC, Chuang LY. Role of the Janus kinase (JAK)/signal transducters and activators of transcription (STAT) cascade in advanced glycation end-product-induced cellular mitogenesis in NRK-49F cells. Biochem J. 1999;342(Pt 1):231-8.

13. Nakajima H, Takenaka M, Kaimori JY, Hamano T, Iwatani H, Sugaya T, Ito T, Hori M, Imai E. Activation of the signal transducer and activator of transcription signaling pathway in renal proximal tubular cells by albumin. J Am Soc Nephrol. 2004;15:276-85.

14. Ogata H, Chinen T, Yoshida T, Kinjyo I, Takaesu G, Shiraishi H, lida M, Kobayashi T, Yoshimura A. Loss of SOCS3 in the liver promotes fibrosis by enhancing STAT3-mediated TGF-beta1 production. Oncogene. 2006;25: 2520-30.

15. Kuratsune M, Masaki T, Hirai T, Kiribayashi K, Yokoyama Y, Arakawa T, Yorioka N, Kohno N. Signal transducer and activator of transcription 3 involvement in the development of renal interstitial fibrosis after unilateral ureteral obstruction. Nephrology (Carlton). 2007;12:565-71.

16. Calvier L, Chouvarine P, Legchenko E, Hoffmann N, Geldner J, Borcher P, Jonigk D, Mozes MM, Hansmann G. PPARgamma links BMP2 and TGFbeta1 pathways in vascular smooth muscle cells, regulating cell proliferation and glucose metabolism. Cell Metab. 2017;25:1118-1134 e1117.

17. Chiarelli F, Di Marzio D. Peroxisome proliferator-activated receptor-gamma agonists and diabetes: current evidence and future perspectives. Vasc Health Risk Manag. 2008;4:297-304

18. Kernan WN, Viscoli CM, Furie KL, Young LH, Inzucchi SE, Gorman M, Guarino PD, Lovejoy AM, Peduzzi PN, Conwit R, et al. Pioglitazone after ischemic stroke or transient ischemic attack. N Engl J Med. 2016;374:1321-31.

19. Wang W, Liu F, Chen N. Peroxisome proliferator-activated receptor-gamma (PPAR-gamma) agonists attenuate the profibrotic response induced by TGFbeta1 in renal interstitial fibroblasts. Mediat Inflamm. 2007;2007:62641.

20. Kawai T, Masaki T, Doi S, Arakawa T, Yokoyama Y, Doi T, Kohno N, Yorioka N. PPAR-gamma agonist attenuates renal interstitial fibrosis and inflammation through reduction of TGF-beta. Lab Investig. 2009;89:47-58.

21. Zhang Y, Wang J, Zhou QD, Zhang CH, Li Q, Huang S, Zhan J, Wang K, Liu YY, XU G. Peroxisome proliferator-activated receptor-gamma agonist pioglitazone fails to attenuate renal fibrosis caused by unilateral ureteral obstruction in mice. J Huazhong Univ Sci Technolog Med Sci. 2016;36:41-7.

22. Kopp JB, Factor VM, Mozes M, Nagy P, Sanderson N, Bottinger EP, Klotman PE, Thorgeirsson SS. Transgenic mice with increased plasma levels of TGFbeta 1 develop progressive renal disease. Lab Investig. 1996;74:991-1003.

23. Czirok S, Fang L, Radovits T, Szabo G, Szenasi G, Rosivall L, Merkely B, Kokeny G. Cinaciguat ameliorates glomerular damage by reducing ERK1/2 activity and TGF-ss expression in type-1 diabetic rats. Sci Rep. 2017;7:11218.

24. Curtis MJ, Alexander S, Cirino G, Docherty JR, George CH, Giembycz MA, Hoyer D, Insel PA, Izzo AA, Ji Y, et al. Experimental design and analysis and their reporting II: updated and simplified guidance for authors and peer reviewers. Br J Pharmacol. 2018;175:987-93.

25. Viau A, El Karoui K, Laouari D, Burtin M, Nguyen C, Mori K, Pillebout E, Berger T, Mak TW, Knebelmann B, et al. Lipocalin 2 is essential for chronic kidney disease progression in mice and humans. J Clin Invest. 2010;120: 4065-76.

26. Soccio RE, Chen ER, Lazar MA. Thiazolidinediones and the promise of insulin sensitization in type 2 diabetes. Cell Metab. 2014;20:573-91.

27. Yang J, Zhou Y, Guan Y. PPARgamma as a therapeutic target in diabetic nephropathy and other renal diseases. Curr Opin Nephrol Hypertens. 2012; 21:97-105.
28. Hansmann G, Wagner RA, Schellong S, Perez VA, Urashima T, Wang L, Sheikh AY, Suen RS, Stewart DJ, Rabinovitch M. Pulmonary arterial hypertension is linked to insulin resistance and reversed by peroxisome proliferator-activated receptor-gamma activation. Circulation. 2007;115: 1275-84.

29. McDonald JA. Extracellular matrix assembly. Annu Rev Cell Biol. 1988;4:183-207.

30. Shoulders MD, Raines RT. Collagen structure and stability. Annu Rev Biochem. 2009;78:929-58.

31. Yoshioka K, Takemura T, Murakami K, Okada M, Hino S, Miyamoto H, Maki S. Transforming growth factor-beta protein and mRNA in glomeruli in normal and diseased human kidneys. Lab Investig. 1993;68:154-63.

32. Liu Y. Renal fibrosis: new insights into the pathogenesis and therapeutics. Kidney Int. 2006;69:213-7.

33. Ma LJ, Marcantoni C, Linton MF, Fazio S, Fogo AB. Peroxisome proliferatoractivated receptor-gamma agonist troglitazone protects against nondiabetic glomerulosclerosis in rats. Kidney Int. 2001;59:1899-910.

34. Benigni A, Zoja C, Tomasoni S, Campana M, Corna D, Zanchi C, Gagliardini E, Garofano E, Rottoli D, Ito T, et al. Transcriptional regulation of nephrin gene by peroxisome proliferator-activated receptor-gamma agonist: molecular mechanism of the antiproteinuric effect of pioglitazone. J Am Soc Nephrol. 2006;17:1624-32.

35. Sivarajah A, Chatterjee PK, Patel NS, Todorovic Z, Hattori Y, Brown PA, Stewart KN, Mota-Filipe H, Cuzzocrea S, Thiemermann C. Agonists of peroxisome-proliferator activated receptor-gamma reduce renal ischemia/ reperfusion injury. Am J Nephrol. 2003;23:267-76.

36. Wynn TA. Cellular and molecular mechanisms of fibrosis. J Pathol. 2008;214: 199-210.

37. Roberts AB, McCune BK, Sporn MB. TGF-beta: regulation of extracellular matrix. Kidney Int. 1992;41:557-9.

38. Wu M, Melichian DS, Chang E, Warner-Blankenship M, Ghosh AK, Varga J. Rosiglitazone abrogates bleomycin-induced scleroderma and blocks profibrotic responses through peroxisome proliferator-activated receptorgamma. Am J Pathol. 2009;174:519-33.

39. Liang $Y$, Jin $Y$, Li Y. Expression of JAKs/STATs pathway molecules in rat model of rapid focal segmental glomerulosclerosis. Pediatr Nephrol. 2009; 24:1661-71

40. Pang M, Ma L, Gong R, Tolbert E, Mao H, Ponnusamy M, Chin YE, Yan H, Dworkin LD, Zhuang S. A novel STAT3 inhibitor, S3I-201, attenuates renal interstitial fibroblast activation and interstitial fibrosis in obstructive nephropathy. Kidney Int. 2010;78:257-68.

\section{Publisher's Note}

Springer Nature remains neutral with regard to jurisdictional claims in published maps and institutional affiliations.

Ready to submit your research? Choose BMC and benefit from:

- fast, convenient online submission

- thorough peer review by experienced researchers in your field

- rapid publication on acceptance

- support for research data, including large and complex data types

- gold Open Access which fosters wider collaboration and increased citations

- maximum visibility for your research: over $100 \mathrm{M}$ website views per year

At $\mathrm{BMC}$, research is always in progress.

Learn more biomedcentral.com/submissions 